\title{
Effects of Word Frequency and Spelling-to-Sound Regularity in Naming With and Without Preceding Lexical Decision
}

\author{
Yasushi Hino \\ Chukyo University
}

\author{
Stephen J. Lupker \\ University of Western Ontario
}

\begin{abstract}
The effects of word frequency and spelling-to-sound regularity were examined using standard naming, standard lexical-decision, go/no-go naming, and go/no-go lexical-decision tasks. In both the standard and go/no-go naming tasks, tasks requiring phonological coding, a significant Frequency $\times$ Regularity interaction was observed. That is, the regularity effect was limited to low-frequency words. In the standard and go/no-go lexical-decision tasks, tasks not requiring phonological coding, no Frequency $\times$ Regularity interaction was observed. These results indicate not only that the Frequency $\times$ Regularity interaction is a product of phonological coding processes but also that these processes are similar in the standard and go/no-go naming tasks. Results are discussed in terms of the dual-route and the parallel distributed processing frameworks.
\end{abstract}

It is a well-documented finding that high-frequency words are responded to faster than are low-frequency words in both lexical-decision tasks (LDTs) and naming tasks (e.g., Balota \& Chumbley, 1984, 1985; Forster \& Chambers, 1973; Hino \& Lupker, 1996; Paap, McDonald, Schvaneveldt, \& Noel, 1987; Rubenstein, Garfield, \& Millikan, 1970). It is also a reasonably well-documented finding that the nature of words' spelling-to-sound correspondences plays a large role in naming and that the size of the word frequency effect in naming is modulated by the degree of spelling-to-sound regularity/consistency (e.g., Frost, Katz, \& Bentin, 1987; Hino \& Lupker, 1998; Monsell, 1991; Monsell, Doyle, \& Haggard, 1989; Plaut, McClelland, Seidenberg, \& Patterson, 1996; Seidenberg, 1992; Seidenberg, Waters, Barnes, \& Tanenhaus, 1984; Van Orden, Pennington, \& Stone, 1990). In particular, the size of the frequency effect is smaller for words with regular/consistent spelling-to-sound correspondences (i.e., regular words) than for words with exceptional correspondences (i.e., irregular words) in naming tasks. ${ }^{1}$ Finally, although it is less clear whether regularity/ consistency plays a role in lexical decision (e.g., Hino \& Lupker, 1996; Stanovich \& Bauer, 1978; Waters \& Seidenberg, 1985), the more typical result is that it does not, except in special circumstances when phonological processing is emphasized by the nature of the task (although, as will be discussed, Stone, Vanhoy, \& Van Orden, 1997, and Ziegler, Montant, \& Jacobs, 1997, have recently provided a different position on this issue).

Yasushi Hino, Department of Psychology, Chukyo University, Nagoya, Japan; Stephen J. Lupker, Department of Psychology, University of Western Ontario, London, Ontario, Canada.

We would like to thank Greg Stone, Ken Pugh, and an anonymous reviewer for their comments on earlier versions of this article.

Correspondence concerning this article should be addressed to Yasushi Hino, Department of Psychology, Chukyo University, 101-2 Yagotohonmachi, Showaku, Nagoya, Aichi, 466-8666, Japan. Electronic mail may be sent to hino@sccs.chukyo-u.ac.jp.
This Frequency $\times$ Regularity/Consistency interaction in naming tasks has been accounted for within the framework of classical word recognition models by applying Coltheart's (1978) dual-route framework to those models (e.g., Besner, in press; Besner \& Smith, 1992; Coltheart, Curtis, Atkins, \& Haller, 1993; Monsell, 1991; Monsell et al., 1989; Paap et al., 1987; Patterson \& Coltheart, 1987). In the classical word recognition models, each word is assumed to be represented by a lexical unit. When a word is being read, an important initial stage in processing involves selecting the lexical unit appropriate to that word (hence, we refer to these models as "lexical-selection models"). Phonological, syntactic, and semantic information are all assumed to become available after that lexical unit has been selected. Most importantly, word frequency effects are assumed to arise during the process of selecting the appropriate lexical unit by assuming either that the lexical units themselves are frequency sensitive (e.g., McClelland \& Rumelhart, 1981; Morton, 1969; Rumelhart \& McClelland, 1982) or that the selection process involves a frequency-ordered serial search (e.g., Becker, 1980; Forster, 1976; Paap, Newsome, McDonald, \& Schvaneveldt, 1982).

This type of account, in and of itself, could not, of course, explain the Frequency $\times$ Regularity/Consistency interaction in naming because regularity/consistency is not assumed to play any role in either the lexical-selection or phonological retrieval processes. To account for this interaction, one must also incorporate the dual-route hypothesis.

According to the dual-route hypothesis, there are at least two independent parallel phonological coding processes.

\footnotetext{
${ }^{1}$ In contrast to the general finding of an interaction between regularity/consistency and frequency in naming tasks, Jared (1997) reported that consistency effects could be observed not only for low-frequency words but also for high-frequency words when the degree of inconsistency for high-frequency inconsistent words is as large as that for low-frequency inconsistent words. The implications of her findings for the present research are discussed in the General Discussion section.
} 
The first process, which is based on the lexical-selection process just discussed, is called the "lexical route" because lexical knowledge is what is used to generate the correct phonological code. The idea is that, as in classical word recognition models, orthographic codes are assumed to be first analyzed to select a lexical unit. After selecting the appropriate lexical unit, a phonological code then becomes available essentially automatically. For our purposes here, we note three points about the working of this route. First, although the lexical route cannot generate phonological codes for letter strings that a reader has never encountered before, it can generate a correct phonological code for any word in the reader's lexicon. Second, because the phonology derived by the lexical route is retrieved from amodal lexical representations, the processing speed of the lexical route would not be modulated by spelling-to-sound regularity/ consistency. Finally, word frequency is assumed to affect the processing speed because the lexical-selection process itself is assumed to be frequency sensitive.

The second phonological coding process, which is called the "assembly route," is assumed to be sensitive to spellingto-sound regularity/consistency but insensitive to word frequency. ${ }^{2}$ The idea here is that phonological codes are assumed to be generated from subword-level orthographic codes by applying spelling-to-sound correspondence rules. That is, phonological coding is accomplished based on graphemic codes (or larger orthographic units) by calculating the corresponding phonemes and then assembling them to produce a phonological code. Because phonological codes are generated by applying spelling-to-sound correspondence rules, this route would generate correct phonological codes only for words that obey the spelling-to-sound correspondence rules (i.e., regular words). For words with exceptional spelling-to-sound correspondences (i.e., irregular, or exception, words), this route would instead generate incorrect, regularized codes. As such, the assembly route would be of little use when naming those words and in fact may even interfere with the naming process. Another important point is that because the assembly route is driven by subword-level orthographic codes, the lexical-selection process is not involved in the workings of this route. Thus, unlike with the lexical route, the processing speed of the assembly route would not be affected by word frequency.

Working under these assumptions, the Frequency $x$ Regularity/Consistency interaction in naming tasks is easily accounted for in terms of the different degrees of contributions of the two routes depending on word type. Because high-frequency words are processed rapidly on the lexical route, the contribution of the assembly route is minimal when naming those words. Because, as noted, the lexical route is insensitive to spelling-to-sound regularity/consistency, the naming of high-frequency words would not be expected to be affected by their spelling-to-sound regularity/ consistency, as is typically reported.

For low-frequency words, however, the processing speed of the lexical route would be slower, and thus the assembly route would produce a phonological code at approximately the same time as, or even earlier than, the lexical route. Thus, the assembly route would contribute to the naming of low-frequency words. Furthermore, the effect of that contribution depends on the nature of the spelling-to-sound correspondences in the word. For low-frequency words with exceptional spelling-to-sound correspondences, the assembly route contributes an incorrect phonological code. Therefore, to initiate a correct naming response, it is necessary to wait for the correct phonological code generated by the lexical route and to resolve any competition between these two codes. Thus, the naming responses would be slowed for these words. On the other hand, for words with regular/ consistent spelling-to-sound correspondences, both routes provide correct codes. Thus, there is no competition and the processing of these words may even gain from this redundancy. As a consequence, word frequency effects would be larger for words with exceptional spelling-to-sound correspondences than for words with regular spelling-to-sound correspondences.

As noted, in the LDT, performance is typically not affected by regularity/consistency unless the nature of the task emphasizes phonological processing (Hino \& Lupker, 1996; Seidenberg et al., 1984; Waters \& Seideneberg, 1985; however, see Pugh et al., 1997; Stone et al., 1997; Ziegler et al., 1997). This result is explained by the assumption that none of the core processes involved in making lexical decisions, most importantly the lexical-selection process, are sensitive to spelling-to-sound regularity/consistency. That is, because the LDT requires a word-nonword discrimination, the task typically requires the responder to complete lexical selection in order to determine whether the presented letter string has a corresponding lexical unit (e.g., Coltheart, 1978; Coltheart et al., 1993). Thus, the lexical-selection process is a core process necessary for making wordnonword decisions. As a result, large frequency effects typically emerge. However, because the lexical-selection process is not sensitive to spelling-to-sound correspondences, the nature of those correspondences does not affect lexical-decision performance.

The lexical-selection/dual-route framework, then, can explain the Frequency $\times$ Regularity/Consistency interaction in naming tasks as well as the lack of a regularity/ consistency effect in LDTs. In addition, this account can also explain the standard result that frequency effects are larger in LDTs than in naming tasks (e.g., Balota \& Chumbley, 1984; Hino \& Lupker, 1998; Monsell, 1991; Monsell et al., 1989; Paap et al., 1987). This account is, however, not the only account that provides a viable explanation for the different

\footnotetext{
${ }^{2}$ According to the most recent description of the dual-route model (Coltheart et al., 1993), the workings of the assembly route are affected only by spelling-to-sound regularity, not by spelling-tosound consistency. (Consistency effects are instead assumed to arise from the lexical route.) As such, regularity was the factor manipulated in the present experiments. Previous versions of the dual-route model have, however, allowed for consistency to also affect the assembly process (e.g., Patterson \& Morton, 1985), and thus it is possible that future versions of the model will as well. Therefore, when discussing the actions of the assembly route at a general level, we allow for the possibility that it may be affected by consistency as well as by regularity by referring to these effects as regularity/consistency effects.
} 
Frequency $\times$ Regularity/Consistency interactions in these tasks. A viable explanation can also be provided based on parallel distributed processing (PDP) models (e.g., Plaut, 1997; Plaut \& McClelland, 1993; Plaut et al., 1996; Seidenberg, 1992; Seidenberg \& McClelland, 1989; Van Orden et al., 1990). Contrary to classical word recognition models, these models postulate no lexical representations or lexicalselection process. Instead of assuming that words are represented as separate lexical units, the PDP framework assumes that each word is represented by a pattern of activation over orthographic, phonological, and semantic units.

In this framework, phonological coding is described as a computation from the orthographic input activation pattern to the output activation pattern over the phonological units. The weights on connections between units are adjusted through learning. Because high-frequency words are seen more frequently than low-frequency words, the weights on connections between the relevant orthographic and phonological units would be greater for high-frequency words. Thus, phonological coding would be faster for highfrequency words than for low-frequency words.

The weights on connections between orthographic input units and phonological output units for any given word are also affected by the processing of similarly spelled words. In particular, the existing weights on connections for a word would increase when the model is exposed to similarly spelled words that have the same spelling-to-sound correspondences, whereas the weights would decrease from exposure to similarly spelled words with different spelling-to-sound correspondences. As a consequence, the phonological computation would be faster for regular/consistent words than for irregular/inconsistent words, especially if those words are low-frequency words. The important point here is that because high-frequency words are viewed so often, their particular (whole word) spelling-to-sound correspondences would be overlearned and strong connections would be established between units. Thus, the weights for highfrequency words would be relatively uninfluenced by the spelling-to-sound correspondences of the similarly spelled words. On the other hand, the weights for low-frequency words would be much more strongly influenced by those correspondences. In particular, the weights for lowfrequency words with consistent spelling-to-sound correspondences would be much stronger than the weights for words with inconsistent spelling-to-sound correspondences, leading to a regularity/consistency effect for low-frequency words. As such, a PDP framework could also account for the Frequency $\times$ Regularity/Consistency interaction observed when a phonological code must be computed in a naming task.

The PDP framework can also account for the lack of the regularity/consistency effects in LDTs. To account for lexical-decision performance, Seidenberg and McClelland (1989) and Plaut (1997) assumed that the core process in that task is a decision-making process that makes use of familiarity indexes. These familiarity indexes can be based on orthographic, phonological, or semantic activation depending on the difficulty and nature of the task. Most importantly,
Seidenberg and $\mathrm{McCl}$ llland suggested that lexical decisions are typically made on the basis of orthographic error scores when the orthographic information provides enough of a clue to make word-nonword decisions. Given an orthographic input activation, an orthographic output activation is computed. The computed orthographic output activation is then compared with the orthographic input activation to produce an orthographic error score for a given stimulus. This orthographic error score is then used as the index of orthographic familiarity by the decision-making process.

In this framework, neither the computation of orthographic error scores nor the decision-making process would be affected by the regularity/consistency of spelling-tosound correspondences. Thus, if the orthographic error scores are the sole source of the index of familiarity at the decision-making level, the regularity/consistency of spellingto-sound correspondences would be irrelevant to lexicaldecision performance.

It should also be noted that a strong case has been made that all implemented PDP models have clear limitations in accounting for human subjects' data in both LDTs (e.g., Besner, Twilley, McCann, \& Seergobin, 1990; Fera \& Besner, 1992) and in naming tasks (e.g., Balota \& Spieler, in press; Besner, in press; Spieler \& Balota, 1997). Nonetheless, the point we wish to make here is that, regardless of the fate of any specific implementations, the general PDP framework, like the lexical-selection/dual-route framework, does appear to provide a reasonable account of how frequency and regularity/consistency typically affect performance in naming and lexical-decision tasks.

Also note that, in the spirit of the claims made by Balota and Chumbley $(1984,1985)$, PDP models account for word frequency effects in terms of task-specific processes such as the decision-making process in LDTs and the phonological coding process in naming tasks. On the other hand, as noted, the lexical-selection/dual-route models suggest that frequency effects are mainly due to the lexical-selection process that is common to these tasks.

Recently, Hino and Lupker (1998) sought to distinguish between these alternative accounts using Japanese kanji and katakana words. Because each katakana character corresponds to a single pronunciation, katakana is considered a shallow orthography that has regular, consistent spelling-tosound correspondences. That is, the same katakana character is always pronounced the same regardless of the word in which the character is embedded. On the other hand, kanji characters generally correspond to at least two pronunciations that are called "kun-reading" (which is an original Japanese pronunciation) and "on-reading" (a pronunciation imported from China). Therefore, contrary to katakana, the same kanji character is pronounced differently depending on the intraword context. Thus, kanji is considered a deep orthography that involves a number of irregular/inconsistent spelling-to-sound correspondences.

Given these characteristics concerning the spelling-tosound correspondences of kanji and katakana scripts, both accounts predict that frequency effects would be modulated by script type (kanji vs. katakana) in a naming task, whereas frequency effects would be identical for kanji and katakana 
words in an LDT (assuming that the frequency manipulation was identical in the two scripts). In fact, Hino and Lupker (1998) did observe similar frequency effects for kanji (110-ms effect) and katakana (105-ms effect) words in an LDT, whereas, using the same kanji and katakana words, the frequency effect was larger for kanji words (94-ms effect) than for katakana words (41-ms effect) in a naming task.

To distinguish between the two accounts, Hino and Lupker (1998) then used a go/no-go naming task. That is, using the same kanji and katakana words, participants were asked to name a stimulus aloud only if it is a word. Lexical-selection/dual-route models would suggest that because lexical-selection (and whatever decision-making operations are involved) needs to be completed before phonological coding in this task, phonological codes should be readily available from the lexical route. Thus, the assembly route should essentially play no role in this task. Therefore, lexical-selection/dual-route models would predict that this task should produce frequency effects identical to those in the LDT and, more important, these effects should not be modulated by script type. ${ }^{3}$

According to PDP models, on the other hand, much different results are predicted in the go/no-go naming task. As noted, PDP models suggest that the decision-making process and the phonological coding process are mainly responsible for producing frequency effects in lexicaldecision and naming tasks, respectively. Working on the assumption that the go/no-go naming task involves both the decision-making process and the phonological computation process in a quasi-sequential order, one prediction these models would make is that the sizes of frequency effects in the go/no-go naming task should be similar to the sum of the frequency effects in the lexical-decision and naming tasks. Thus, the sizes of frequency effects should be larger in the go/no-go naming task than in the LDT. More important, because the phonological computation process is driven by orthographic input activation in both the standard and go/no-go naming tasks, rather than by lexical activation, the go/no-go naming task should also produce a Frequency $\times$ Script Type interaction, with the frequency effect being larger for kanji words than for katakana words.

The results of the go/no-go naming task was consistent with the latter predictions. That is, frequency effects were larger for kanji words (177-ms effect) than for katakana words (123-ms effect), and these effect sizes were significantly larger than those in the LDT.

Although the lexical-selection/dual-route framework failed to predict the go/no-go naming results, Hino and Lupker (1998) suggested that it may be possible to account for these results in terms of this framework if some extra assumptions were added. The first problem was how to explain the larger frequency effects in the go/no-go naming task (177-ms effect) than in either the LDT (110-ms effect) or the naming task (94-ms effect) for kanji words, words that supposedly require lexical selection in order to be named. In both instances, one needs to assume that there is a process that is involved in the go/no-go naming task but not in the other tasks that is frequency sensitive. Consider first the contrast between the lexical-decision and go/no-go naming tasks.
According to the lexical-selection/dual-route framework, both tasks require the lexical-selection process and decisionmaking operations. Where they differ is that the go/no-go naming task also requires a (lexically based) phonological coding process whereas lexical decision does not. Thus, if one assumes that this process takes place only after the decision-making process is completed and that it is frequency sensitive (see McCann \& Besner, 1987), the larger frequency effect in go/no-go naming than in lexical decision could be explained.

A similar explanation can be applied to account for the larger frequency effect for kanji words in the go/no-go naming task than in the standard naming task. That is, this difference would suggest that there is a process that is involved in the go/no-go naming task but not in the standard naming task that is frequency sensitive. For kanji words, both tasks seem to involve lexical selection as well as the lexical phonological coding process. Thus, the additional process that appears to be involved only in the go/no-go naming task would be the decision-making process. There are in fact a number of results in the literature that support the argument that this process is frequency sensitive (e.g., Balota \& Chumbley, 1984; Besner, 1983; Besner \& McCann, 1987). Thus, the assumption of a frequency-sensitive decision-making process would appear to be a reasonable (and necessary) one to add to the lexical-selection/dual-route framework. With these assumptions, then, it is possible to account for the larger frequency effects in go/no-go naming than in either lexical decision or standard naming (of kanji words; as reported by Hino \& Lupker, 1998) within this framework.

What still must be accounted for, however, is Hino and Lupker's (1998) report of a Frequency $\times$ Script Type interaction in the go/no-go naming task. In the lexicalselection/dual-route framework, the Frequency $\times$ Script Type interaction in the standard naming task can be accounted for in terms of the greater contribution of the assembly route to the naming of low-frequency katakana words relative to the naming of low-frequency kanji words. However, because lexical selection is assumed to be completed before phonological coding in the go/no-go naming task, there is no reason that the assembly route would play any role in the go/no-go naming task. Thus, for lexicalselection/dual-route models to account for the Frequency $x$ Script Type interaction in the go/no-go naming task, there needs to be a mechanism by which this interaction can arise during the lexical phonological coding process. That is, there needs to be a mechanism by which the lexical phonological coding process can be sensitive to both script type and word frequency.

The fact that these studies were carried out in Japanese allowed Hino and Lupker (1998) to raise an interesting

\footnotetext{
${ }^{3}$ The analysis that Hino and Lupker (1998) used was based on the assumption that the implicit lexical decision in a go/no-go naming task precedes phonological coding. For ease of exposition, we make the same assumption in this article. Alternative processing assumptions and the impact that they might have on the conclusions reached are considered in the General Discussion section.
} 
possibility. Although it is possible to write most Japanese words in either kanji, katakana, or hiragana, any particular word tends to always be written in the same script. Thus, it is possible that the lexical units for Japanese readers may be script dependent. If so, because the lexical phonological coding process would be driven by script-dependent lexical units, it is possible that the frequency effects arising during this process would be modulated by orthographic differences between kanji and katakana words. Thus, a Frequency $\times$ Script Type interaction in go/no-go naming may result.

In the present research, we examined the viability of the hypothesis that the Frequency $\times$ Script Type interaction that Hino and Lupker (1998) observed in go/no-go naming was due to script-dependent lexical units for Japanese readers. Although it is possible that lexical units are, at least to some extent, script dependent in Japanese, there would be no parallel difference between lexical units for regular and irregular words in English. As such, spelling-to-sound regularity/consistency should not affect a lexical phonological coding process in English, and certainly it should not affect one that takes place only after a decision-making process has been completed. Thus, there should be no Frequency $\times$ Regularity interaction in go/no-go naming in English. On the other hand, if the Frequency $\times$ Script Type interaction were due to the fact that frequency interacts with spelling-to-sound regularity/consistency during phonological computation as described by PDP models, a Frequency $X$ Regularity interaction should also be observed in the go/ no-go naming task using regular and irregular English words.

Parallelling the manipulations of Hino and Lupker (1998), then, we examined the effects of word frequency for regular and irregular English words using lexical-decision, naming, and go/no-go naming tasks. To replicate the findings that frequency effects are modulated by regularity in naming but not in lexical decision, we initially conducted a standard LDT (Experiment 1) and a standard naming task (Experiment 2).

\section{Experiment 1}

\section{Method}

Participants. Twenty-six undergraduate students from the University of Western Ontario participated in this experiment for course credit. All were native English speakers and had normal or corrected-to-normal vision.

Stimuli. All the stimuli were four letters long. Forty regular and 40 irregular words were collected from the previous literature (e.g., Hino \& Lupker, 1996; Seidenberg et al., 1984; Waters \& Seidenberg, 1985). Half the regular and irregular words were high-frequency words. Frequency counts for the high-frequency words were greater than or equal to 70 per million according to Kucera and Francis's (1967) norms. The other half were lowfrequency words, and their frequency counts were less than or equal to 30 per million.

After collecting these 80 words, 24 participants were asked to rate the experiential familiarity for each word. The 80 words were randomly ordered and listed in a questionnaire. Each word was accompanied by a 7-point scale with rating values ranging from very unfamiliar (1) to very familiar (7). The participants were then asked to rate the experiential familiarity for each word by circling the appropriate number on the scale.

On the basis of the rating data, we selected 48 words ( 12 words for each group) to create four word groups in which frequency (high or low) and regularity (regular or irregular) were orthogonally manipulated. All the irregular words selected were classified as irregular according to Venezky's (1970) rules. The word frequency counts and the experiential familiarity rating values were closely matched between regular and irregular word groups. In addition, mean positional bigram frequency (Mayzner \& Tresselt, 1965) and orthographic neighborhood size (Coltheart, Davelaar, Jonasson, \& Besner, 1977) were matched across the four word groups.

To ensure that the four word groups had been selected properly, we conducted analyses of variance (ANOVAs) on all the relevant factors: word frequency, orthographic neighborhood size, mean bigram frequency, and experiential familiarity ratings. For word frequency, the main effect of frequency was significant, $F(1,44)=$ $61.21, M S E=14,584.82, p<.001$, but the main effect of regularity, $F(1,44)=.07, M S E=14,584.82$, and the interaction between frequency and regularity, $F(1,44)=.06, M S E=$ $14,584,82$, were not significant. The same results were obtained for the experiential familiarity ratings: frequency, $F(1,44)=194.61$, $M S E=0.518, p<.001 ;$ regularity, $F(1,44)=0.94, M S E=0.518$ interaction, $F(1,44)=0.73, M S E=0.518$. No significant effects were detected either for orthographic neighborhood size, frequency, $F(1,44)=0.00, M S E=8.78$; regularity, $F(1,44)=0.15$, $M S E=8.78$; interaction, $F(1,44)=0.47, M S E=8.78$; or for mean bigram frequency, frequency, $F(1,44)=1.10, M S E=$ 557.58; regularity, $F(1,44)=0.03, M S E=557.58$; interaction, $F(1,44)=0.58, M S E=557.58$.

The experimental word stimuli are listed in the Appendix. The statistical characteristics of these words are shown in Table 1.

In addition to the 48 experimental word stimuli, 12 filler words and 40 nonwords were added. Thus, the entire stimulus set consisted of 100 stimuli. All the nonwords were pronounceable nonwords (none were pseudohomophones) and were created by replacing one letter from actual words. The nonwords are also presented in the Appendix.

Procedure. Participants were tested individually in a normally lit room. They were asked to make a word-nonword discrimination for a stimulus appearing on a video monitor (CMS-3436, Multiscan monitor) by pressing either the word or nonword key on a response box. They were also told that their responses should be made as quickly and as accurately as possible. Twenty-two practice trials were given before the 100 experimental trials. During the practice trials, participants were informed about their lexical-decision latency and accuracy after each trial. No feedback was given during the experimental trials. The order of stimulus presentation for the experimental trials was randomized for each participant.

Each trial was initiated with a $50-\mathrm{ms}, 400-\mathrm{Hz}$ beep signal. After

Table 1

Mean Word Frequency (Freq), Word Length (Len), Orthographic Neighborhood Size (N), Positional Bigram Frequency $(B F)$, and Experiential Familiarity Rating (FAM) for the Stimuli in Experiments 1-5

\begin{tabular}{lrcccc}
\hline $\begin{array}{c}\text { Frequency/ } \\
\text { regularity }\end{array}$ & Freq & Len & N & BF & FAM \\
\hline Low/regular & 8.1 & 4.0 & 11.3 & 78.3 & 2.85 \\
Low/irregular & 8.7 & 4.0 & 10.3 & 71.9 & 2.87 \\
High/regular & 272.4 & 4.0 & 10.7 & 80.2 & 5.57 \\
High/irregular & 289.8 & 4.0 & 10.9 & 84.2 & 5.95 \\
\hline
\end{tabular}


the beep, a fixation point appeared at the center of the video monitor. One second after the onset of the fixation point, a stimulus was presented in capital letters above the fixation point. Participants were seated in front of the video monitor at a distance of about $50 \mathrm{~cm}$ and were asked to respond to the stimulus by pressing either the word or nonword key on the response box interfaced to a computer (AMI 386 Mark II). The "word" response was made using the participant's dominant hand. The participant's response terminated the presentation of the stimulus and the fixation point. Lexical-decision latencies from the onset of the stimulus to the participant's keypress and errors were recorded by the computer. The intertrial interval was $2 \mathrm{~s}$.

\section{Results}

Lexical-decision latencies less than $250 \mathrm{~ms}$ or greater than $1500 \mathrm{~ms}$ were classified as errors. Thus, 2 data points from the experimental word trials $(0.16 \%)$ were considered as errors and excluded from the latency analyses. Mean lexical decision latencies for correct responses and mean error rates were calculated across participants and items separately. The mean lexical decision latencies and error rates (based on the 48 experimental word trials) averaged over the participants are presented in Table 2.

Subject and item means of lexical-decision latencies and error rates (based on the experimental word trials) were submitted to separate ANOVAs. ${ }^{4}$ In the analyses of lexicaldecision latencies, the main effect of frequency was significant both in the subject $(s)$ and the item $(i)$ analyses, $F_{s}(1$, $25)=135.37, M S E=1,792.10, p<.001 ; F_{i}(1,44)=$ 43.83, $M S E=2,885.60, p<.001$, reflecting the fact that lexical-decision latencies were faster for high-frequency words than for low-frequency words. Neither the main effect of regularity, $F_{s}(1,25)=0.23, M S E=1,816.70 ; F_{i}(1,44)=$ $0.11, M S E=2,885.60$, or the interaction between frequency and regularity, $F_{s}(1,25)=0.34, M S E=1,257.91 ; F_{i}(1$, $44)=0.03, M S E=2,885.60$, was significant in either analysis.

In the analyses of error rates, the main effect of frequency was significant in both analyses, $F_{s}(1,25)=25.49, M S E=$ $70.84, p<.001 ; F_{i}(1,44)=8.27, M S E=100.80, p<.01$, reflecting the fact that responses to high-frequency words were more accurate than responses to low-frequency words. Neither the main effect of regularity, $F_{s}(1,25)=.34, M S E=$ $69.87 ; F_{i}(1,44)=0.11, M S E=100.80$, nor the interaction

Table 2

Mean Lexical-Decision Latencies (in ms) and Error Rates (\%) in the Standard Lexical-Decision Task in Experiment 1

\begin{tabular}{|c|c|c|c|c|c|}
\hline \multirow[b]{3}{*}{ Regularity } & \multicolumn{4}{|c|}{ Word frequency } & \multirow{3}{*}{$\underset{\text { difference }}{\mathbf{R T}}$} \\
\hline & \multicolumn{2}{|c|}{ Low } & \multicolumn{2}{|c|}{ High } & \\
\hline & $M$ & ER & $M$ & ER & \\
\hline $\begin{array}{l}\text { Regular } \\
\text { Irregular } \\
\text { RT difference }\end{array}$ & $\begin{array}{r}635 \\
635 \\
0\end{array}$ & $\begin{array}{l}10.26 \\
11.54\end{array}$ & $\begin{array}{r}543 \\
535 \\
-8\end{array}$ & $\begin{array}{l}2.24 \\
2.88\end{array}$ & $\begin{array}{r}92 \\
100\end{array}$ \\
\hline
\end{tabular}

Note. Mean lexical-decision latency and error rate for nonwords were $719 \mathrm{~ms}$ and $11.73 \%$, respectively. $\mathrm{ER}=$ error rate; $\mathrm{RT}=$ reaction time. between frequency and regularity $F_{s}(1,25)=0.04, M S E=$ 59.62; $F_{i}(1,44)=0.01, M S E=100.80$, was significant in either analysis.

\section{Discussion}

Whereas significant frequency effects were observed for both lexical-decision latencies and error rates, regularity effects were not. In addition, the lack of a significant Frequency $\times$ Regularity interaction clearly reflects the fact that frequency effects were identical for regular $(92 \mathrm{~ms})$ and irregular words $(100 \mathrm{~ms})$ in this experiment. That is, consistent with much of the previous literature (e.g., Hino \& Lupker, 1996; Seidenberg et al., 1984; Waters \& Seidenberg, 1985), we also observed no effects of regularity on LDT performance.

As noted earlier, there has been some controversy about the existence of regularity effects in LDTs. Although null effects have been the more common result, reports of regularity effects do exist (e.g., Parkin, 1982; Parkin \& Underwood, 1983; Stanovich \& Bauer, 1978). Recently, Stone et al. (1997) suggested that a key factor in determining whether regularity effects will be obtained is whether the words used are "feedback consistent."

The concept of feedback consistency is based on the idea that in a fully interactive system, activation will feed back from higher level phonological units to lower level orthographic units. Depending on the nature of the reader's language, that feedback may be directed to only one orthographic form (hence, the feedback is "consistent") or to more than one orthographic form (hence, the feedback is "inconsistent"). More concretely, some phonological forms (e.g., the rime "afe" in words like safe) have only one way that they can be spelled in English and hence their phonology would provide feedback to a single orthographic form, making safe a feedback-consistent word. For other phonological forms (e.g., the rime "ane" in words like sane), there are at least two ways that they could be spelled (i.e., sane or sain); thus, those types of phonological forms provide feedback to multiple orthographic forms, making words containing them feedback inconsistent.

Stone et al. (1997; see also Ziegler et al., 1997) argued that feedback inconsistency is important in LDTs and, most relevant to the present situation, showed it to interact with regularity (which they referred to as "feedforward consistency"). Specifically, they only observed a regularity effect

\footnotetext{
4 Although Clark (1973) argued that items as well as subjects should be considered as a random factor in these types of analyses, it is seldom the case that the selection of items ever is random in any sense of the word. That is, the items used in these types of experiments typically have been selected because they satisfied an extensive set of criteria. Such is certainly the case here (e.g., see Table 1). As such, as Wike and Church (1976) and others (Cohen, 1976; Keppel, 1976; Smith, 1976) have argued, item analyses would clearly be inappropriate in the present situation for several reasons; not the least of which is their profound negative bias. Nonetheless, for interested readers, we report the results of item analyses. Our conclusions, however, were based only on the results from the subject analyses.
} 
(i.e., a feedforward consistency effect) when using feedbackconsistent words. Furthermore, they determined that most of the words in the English language are feedback inconsistent. Thus, if regular and irregular words are selected without thought to feedback consistency, most selected words will be feedback inconsistent and hence those words will show no regularity effect. In fact, the suggestion is that the inconsistencies in the previous research on this issue may have arisen because of a lack of control of feedback inconsistency.

As is typical, in the present experiment, almost all the words (42 of 48 in total and 10 of 12 in both of the low-frequency conditions) were feedback inconsistent. Thus, the fact that we obtained no regularity effect in Experiment 1 is just as compatible with the Stone et al. (1997) account as it is with the lexical-selection/dual-route account. What should be noted, however, is that more recently, Peereman, Content, and Bonin (1998) demonstrated that the effects reported by Stone et al. and the parallel effects reported by Ziegler et al. (1997) may have been due not to feedback consistency but to uncontrolled effects of experiential familiarity. Thus, it is not clear that the Stone et al. account is a viable one.

Regardless of how this issue is ultimately resolved, its implications for the present research are minor. The question we are asking here is whether the pattern we observe in go/no-go naming parallels whatever pattern we observe in lexical decision (as would be predicted by the lexicalselection/dual-route account) or whether the pattern parallels that obtained in naming (as it did in Hino \& Lupker, 1998). Thus, although it certainly is important that we do not obtain inexplicable data patterns in either our lexicaldecision or naming experiments, the most important issue is that same stimuli be used throughout these experiments.

\section{Experiment 2}

Although frequency effects were not modulated by regularity in the LDT of Experiment 1, previous literature (e.g., Andrews, 1982; Brown, Lupker, \& Colombo, 1994; Hino \& Lupker, 1996; Seidenberg et al., 1984; Waters \& Seidenberg, 1985) suggests that a Frequency $\times$ Regularity interaction almost inevitably appears in a standard naming task. In Experiment 2 we used a standard naming task with the same word stimuli as in Experiment 1. What we expected to find was the typical interaction between frequency and regularity.

\section{Method}

Participants. Twenty-six undergraduates from the University of Western Ontario participated in this experiment for course credit. All were native English speakers and had normal or corrected-tonormal vision. None had participated in Experiment 1.

Stimuli. The stimuli were the 60 word stimuli (48 experimental and 12 fillers) used in Experiment 1.

Procedure. Participants were tested individually in a normally lit room. They were asked to name a word aloud that appeared on a video monitor as quickly and as accurately as possible. Twelve practice trials were given before the 60 experimental trials. During the practice trials, participants were informed of their naming latency after each trial. No feedback was given during the experimental trials. The order of stimulus presentation for the experimental trials was randomized for each participant.

On each trial, the stimulus was presented in the same manner as in Experiment 1. Participants' vocal responses were registered by a microphone connected to a voice key interfaced to the computer. A vocal response terminated the stimulus presentation. Naming latency was measured from the onset of the stimulus to the onset of the vocal response. During the experimental trials, an experimenter sat behind the participant and recorded errors. The intertrial interval was $2 \mathrm{~s}$.

\section{Results}

A trial was considered a mechanical error if the participant's vocal response failed to trigger the voice key or some extraneous sound triggered the voice key. There were 16 mechanical errors in the experimental word trials $(1.28 \%)$. These mechanical errors were excluded from the data analysis. Because all the naming latencies for the correct responses to the experimental word stimuli were between 250 and 1,000 ms, we did not regard any data points as outliers. Mean naming latencies for correct responses and mean error rates were calculated separately across participants and items. The mean naming latencies and error rates (based on the 48 experimental word trials) averaged over the participants are presented in Table 3.

Subject and item means for naming latencies and error rates (based on the experimental word trials) were submitted to separate ANOVAs. In the analyses of naming latencies, the main effect of frequency was significant both in the subject and the item analyses, $F_{s}(1,25)=33.24, M S E=$ $397.20, p<.001 ; F_{i}(1,44)=9.54, M S E=1,012.56, p<$ .01 , reflecting the fact that naming latencies were faster for high-frequency words than for low-frequency words. The main effect of regularity was also significant in both analyses, $F_{s}(1,25)=26.86, M S E=120.60, p<.001 ; F_{i}(1$, 44) $=4.35, M S E=1,012.56, p<.05$. Thus, naming latencies were faster for regular words than for irregular words. In addition, the interaction between frequency and regularity was significant in the subject analysis, $F_{s}(1,25)=$ $11.94, M S E=215.27, p<.01$, and marginally significant in the item analysis, $F_{i}(1,44)=2.83, M S E=1,012.56, p<$ .10 , reflecting the fact that the regularity effect was limited to low-frequency words.

Planned comparisons were used to examine the difference between regular and irregular words for each frequency condition. The regularity effect was significant for low-

Table 3

Mean Naming Latencies (in ms) and Error Rates (\%) in the Standard Naming Task in Experiment 2

\begin{tabular}{|c|c|c|c|c|c|}
\hline \multirow[b]{3}{*}{ Regularity } & \multicolumn{4}{|c|}{ Word frequency } & \multirow{3}{*}{$\begin{array}{c}\mathbf{R T} \\
\text { difference }\end{array}$} \\
\hline & \multicolumn{2}{|c|}{ Low } & \multicolumn{2}{|c|}{ High } & \\
\hline & $M$ & ER & $M$ & ER & \\
\hline $\begin{array}{l}\text { Regular } \\
\text { Irregular } \\
\text { RT difference }\end{array}$ & $\begin{array}{r}464 \\
485 \\
21\end{array}$ & $\begin{array}{r}1.66 \\
15.82\end{array}$ & $\begin{array}{r}452 \\
453 \\
1\end{array}$ & $\begin{array}{l}1.60 \\
2.56\end{array}$ & $\begin{array}{l}12 \\
32\end{array}$ \\
\hline
\end{tabular}

Note. $\mathrm{ER}=$ error rate; $\mathrm{RT}=$ reaction time. 
frequency words, $t_{s}(25)=6.80, p<.001 ; t_{i}(22)=2.40, p<$ .05 , but not for high-frequency words, $t_{s}(25)=0.30$; $t_{i}(22)=0.32$.

In the analyses of error rates, the main effect of frequency was significant in the subject analysis, $F_{s}(1,25)=50.24$, $M S E=22.94, p<.001$, but not in the item analysis, $F_{i}(1$, $44)=2.57, M S E=217.52, p>.10$. The main effect of regularity was significant in the subject analysis, $F_{s}(1,25)=$ 92.01, $M S E=16.16, p<.001$, and marginally significant in the item analysis, $F_{i}(1,44)=3.48, M S E=217.52, p<.07$. Furthermore, the interaction between frequency and regularity was significant in the subject analysis, $F_{s}(1,25)=80.03$, $M S E=14.15, p<.001$, but not in the item analysis, $F_{i}(1$, $44)=2.56, M S E=217.52, p>.10$, reflecting the comparatively higher error rate for low-frequency irregular words.

\section{Discussion}

In contrast to the lack of any effects of regularity in the LDT, the Frequency $\times$ Regularity interaction was significant for both naming latencies and error rates in the standard naming task. In particular, a significant regularity effect was observed only for low-frequency words, or, looked at another way, frequency effects were larger for irregular words than for regular words. Thus, consistent with previous literature (e.g., Andrews, 1982; Brown et al., 1994; Hino \& Lupker, 1996; Seidenberg et al., 1984; Waters \& Seidenberg, 1985), frequency effects were modulated by spelling-tosound regularity in the standard naming task.

\section{Experiment 3}

Although the results of Experiment 2 were as expected, before proceeding we want to resolve an additional issue. As shown in Table 1, the experimental words were equated on a number of dimensions across four word groups. What the word groups were not matched on was first phonemes. Thus, it is possible that articulation onset differences differentially affected naming latencies for words in the different groups.

To address this issue, in Experiment 3 we used a delayed naming task and the words from Experiments 1 and 2. We expected that although there could be small frequency effects (Balota \& Chumbley, 1985; Theios \& Muise, 1977) in this task, there should be no regularity effect.

\section{Method}

Participants. Eighteen undergraduates from the University of Western Ontario participated in this experiment for course credit. All were native English speakers and had normal or corrected-tonormal vision. None had participated in the previous experiments.

Stimuli. The stimuli were the 60 word stimuli ( 48 experimental and 12 fillers) used in Experiments 1 and 2.

Procedure. Participants were tested individually. They were told that a word would appear on the video monitor and that it would be surrounded by brackets after a delay. Participants were asked to name the word aloud as quickly and as accurately as possible as soon as the word was surrounded by the brackets. On each trial, a fixation point and a word stimulus were presented in the same manner as in Experiments 1 and 2. The word stimulus was then surrounded by brackets $1,500 \mathrm{~ms}$ after the onset of its presentation. The delayed naming latency from the onset of the brackets to the onset of the participant's vocal response was recorded. In all other ways, the procedure was identical to that used in Experiment 2.

\section{Results}

A trial was considered a mechanical error if the participant's yocal response failed to trigger the voice key or some extraneous sound triggered the voice key. There were nine mechanical errors in the experimental trials $(1.04 \%)$. These mechanical errors were excluded from the data analyses. In addition, when a delayed naming latency was less than 50 $\mathrm{ms}$ or more than $1,000 \mathrm{~ms}$, the trial was considered an error. Thus, 18 additional data points from the experimental word trials $(2.08 \%)$ were considered as errors and removed from the latency analyses. Mean delayed naming latencies for correct responses and mean error rates (based on the 48 experimental word trials) were calculated across participants and items separately. The mean delayed naming latencies and error rates averaged over the participants are presented in Table 4.

Subject and item means for delayed naming latencies and error rates (based on the experimental word trials) were submitted to separate ANOVAs. In the analyses of delayed naming latencies, neither the main effect of frequency, $F_{s}(1$, 17) $=1.48, M S E=1,147.07 ; F_{i}(1,44)=2.21, M S E=$ 527.55 , nor the main effect of regularity, $F_{s}(1,17)=0.73$, $M S E=741.25 ; F_{i}(1,44)=0.55, M S E=527.55$, nor the interaction between frequency and regularity, $F_{s}(1,17)=$ $0.22, M S E=1095.34 ; F_{i}(1,44)=0.24, M S E=527.55$, was significant in either analysis.

In the analyses of error rates, neither the main effect of frequency, $F_{s}(1,17)=1.15, M S E=41.14 ; F_{i}(1,44)=0.91$, $M S E=38.87$, nor the main effect of regularity, $F_{s}(1,17)=$ $2.28, M S E=20.71 ; F_{i}(1,44)=0.88, M S E=38.87$, nor the interaction between frequency and regularity, $F_{s}(1,17)=$ $1.09, M S E=22.08 ; F_{i}(1,44)=0.46, M S E=38.87$, was significant in either analysis.

\section{Discussion}

No significant effects were observed for either delayed naming latencies or error rates. Thus, the Frequency $x$

Table 4

Mean Naming Latencies (in ms) and Error Rates (\%) in the Delayed Naming Task in Experiment 3

\begin{tabular}{|c|c|c|c|c|c|}
\hline \multirow[b]{3}{*}{ Regularity } & \multicolumn{4}{|c|}{ Word frequency } & \multirow{3}{*}{$\underset{\text { difference }}{\mathbf{R T}}$} \\
\hline & \multicolumn{2}{|c|}{ Low } & \multicolumn{2}{|c|}{ High } & \\
\hline & $M$ & ER & $M$ & ER & \\
\hline Regular & 366 & 2.78 & 360 & 2.31 & 6 \\
\hline Irregular & 364 & 5.55 & 351 & 2.78 & 13 \\
\hline RT difference & -2 & & -9 & & \\
\hline
\end{tabular}

Note. $\quad \mathrm{ER}=$ error rate; $\mathrm{RT}=$ reaction time. 
Regularity interaction in the standard naming task could not be attributed to any articulation onset differences among word groups.

\section{Experiment 4}

Using our regular and irregular English words, we successfully replicated the findings that frequency effects are modulated by regularity in the standard naming task but not in the standard LDT. Thus, to this point, our results have been highly consistent with the lexical-selection/dual-route account. As in Hino and Lupker (1998), we now turn to the question of whether this account could explain the results in a go/no-go naming task.

The specific question asked in Experiment 4 was whether there would be a Frequency $\times$ Regularity interaction in go/no-go naming in English. As discussed previously, with certain assumptions, the lexical-selection/dual-route framework could account for differences in the sizes of the frequency effects in go/no-go naming and LDTs. It could also account for a Frequency $\times$ Script Type interaction in Japanese (Hino \& Lupker, 1998) if one assumes that lexical units are script dependent for Japanese readers. On the other hand, an interaction between frequency and regularity in the go/no-go naming task in English would be much more difficult for the lexical-selection/dual-route framework to account for and would be much more consistent with a PDP framework. This is because frequency and regularity effects both arise because of the nature of the weights on connections between the orthographic and phonological units, weights that are used to compute phonological codes in all naming tasks. To evaluate these predictions, Experiment 4 was a go/no-go naming task using the same materials as those used in Experiment 1.

\section{Method}

Participants. Twenty-six undergraduates from the University of Western Ontario participated in this experiment for course credit. All were native English speakers and had normal or corrected-tonormal vision. None had participated in the previous experiments.

Stimuli. The stimuli were the same as those used in Experiment 1.

Procedure. Participants were tested individually. They were asked to name a stimulus aloud into a microphone only if the stimulus was a word. They were also told that their responses should be as quick and as accurate as possible. On each trial, a stimulus was presented in the same manner as in Experiment 1 . The stimulus remained on the video monitor either until the participant responded or until $2 \mathrm{~s}$ had elapsed. Participants' vocal responses were collected through a microphone connected to a computer via a voice key. Response latency was measured from the onset of the stimulus to the onset of the participant's vocal response. An experimenter sat behind the participant and checked the responses to record errors. In all other ways, the procedure was identical to that used in Experiment 1.

\section{Results}

A trial was considered a mechanical error if the participant's vocal response failed to trigger the voice key or some extraneous sound triggered the voice key. There were 25 mechanical errors in the experimental word trials $(2.00 \%)$. These mechanical errors were excluded from the data analyses. In addition, response latencies less than $250 \mathrm{~ms}$ or greater than $1,500 \mathrm{~ms}$ were classified as errors and excluded from the latency analyses. Thus, 5 additional data points from the experimental word trials $(0.40 \%)$ were also excluded in this fashion. Mean response latencies for correct responses and mean error rates were calculated across participants and items separately. The mean response latencies and error rates (based on the 48 experimental word trials) averaged over the participants are presented in Table 5.

Subject and item means of response latencies and error rates (based on the experimental word trials) were submitted to separate ANOVAs. In the analysis of response latencies, the main effect of frequency was significant both in the subject and the item analyses, $F_{s}(1,25)=117.10, M S E=$ $2,869.89, p<.001 ; F_{i}(1,44)=38.27, M S E=4,636.57, p<$ .001 , reflecting the fact that response latencies were faster for high-frequency words than for low-frequency words. The main effect of regularity was significant in the subject analysis, $F_{s}(1,25)=5.14, M S E=937.59, p<.05$, but not in the item analysis, $F_{i}(1,44)=0.86, M S E=4,636.57, p>$ .10. Most importantly, the interaction between frequency and regularity was also significant in the subject analysis, $F_{s}(1,25)=4.82, M S E=1,961.26, p<.05$, but not in the item analysis, $F_{i}(1,44)=1.29, M S E=4,636.57, p>.10$.

Planned comparisons were used to examine the difference between regular and irregular words for each frequency condition. For low-frequency words, the regularity effect was significant in the subject analysis, $t_{s}(25)=2.46, p<$ .025 , but not in the item analysis, $t_{i}(22)=1.15, p>.10$. For high-frequency words, however, the difference was not significant in either analysis, $t_{s}(25)=0.80 ; t_{i}(22)=0.24$.

In the analyses of error rates, the main effect of frequency was significant in both analyses, $F_{s}(1,25)=38.35, M S E=$ $32.88, p<.001 ; F_{i}(1,44)=6.92, M S E=82.85, p<.025$, reflecting the fact that responses to high-frequency words were more accurate than those to low-frequency words. The main effect of regularity was significant in the subject analysis, $F_{s}(1,25)=5.34, M S E=43.89, p<.05$, but not in the item analysis, $F_{i}(1,44)=1.34, M S E=82.85, p>.10$. The interaction between frequency and regularity was also significant in the subject analysis, $F_{s}(1,25)=5.47, M S E=$

Table 5

Mean Response Latencies (in ms) and Error Rates (\%) in the Go/No-Go Naming Task in Experiment 4

\begin{tabular}{|c|c|c|c|c|c|}
\hline \multirow[b]{3}{*}{ Regularity } & \multicolumn{4}{|c|}{ Word frequency } & \multirow{3}{*}{$\underset{\text { difference }}{\mathbf{R T}}$} \\
\hline & \multicolumn{2}{|c|}{ Low } & \multicolumn{2}{|c|}{ High } & \\
\hline & $M$ & ER & $M$ & ER & \\
\hline $\begin{array}{l}\text { Regular } \\
\text { Irregular } \\
\text { RT difference }\end{array}$ & $\begin{array}{r}699 \\
732 \\
33\end{array}$ & $\begin{array}{r}4.92 \\
10.61\end{array}$ & $\begin{array}{r}605 \\
599 \\
-6\end{array}$ & $\begin{array}{l}0.64 \\
0.96\end{array}$ & $\begin{array}{r}94 \\
133\end{array}$ \\
\hline
\end{tabular}

Note. The mean error rate for nonwords was $4.82 \%$. ER $=$ error rate; $\mathrm{RT}=$ reaction time. 
$34.17, p<.05$, but not in the item analysis $F_{i}(1,44)=1.09$, $M S E=82.85$, reflecting the fact that more errors were made to low-frequency irregular words than to low-frequency regular words, whereas error rates were comparable for high-frequency regular and irregular words.

\section{Discussion}

A Frequency $\times$ Regularity interaction was observed for both latencies and error rates in the go/no-go naming task. In particular, the regularity effect was limited to low-frequency words. Thus, contrary to the hypothesis that the Frequency $\times$ Regularity interaction in go/no-go naming is limited to the case in which lexical units might be sensitive to orthographic characteristics (i.e., Japanese scripts), the Frequency $\times$ Regularity interaction is observed even in languages such as English in which there are no orthographic differences between regular and irregular words.

As we noted in Footnote 3, item ANOVAs were not appropriate in the present circumstances, and thus we report the results of those ANOVAs only for the information of interested readers. The conclusions drawn in this article were based only on the results from the subject analyses. However, because the Frequency $\times$ Regularity interaction in the present experiment was the most important finding in the present research and it was not significant in the item ANOVA, we think that further discussion of why we feel the item analyses were inappropriate is in order.

First, item analyses are based on the idea that the items in the various conditions have been selected randomly. That is, the denominator of the $F$ ratio is calculated in a way that protects against the possibility that when one selects words randomly, the word conditions can vary in terms of uncontrolled but important factors such as frequency or neighborhood size just by chance. When one instead equates word groups on a number of these dimensions (rather than selecting stimuli randomly), this level of protection is inappropriate and in fact leads to a negatively biased $F$ because the denominator of this $F$ is too large (for an additional discussion of these issues, see Wike and Church's, 1976 response to Clark, 1973, as well as the response of others-Cohen, 1976, Keppel, 1976, and Smith, 1976).

In the present circumstance, we clearly did match our stimuli on a number of dimensions. Most importantly, we matched rated familiarity for regular and irregular words because, as Gernsbacher (1984) suggested, experiential familiarity is a strong determinant of response latencies in word recognition tasks. In fact, as noted, Peereman et al. (1998) argued that Stone et al.'s (1997) and Ziegler et al.'s (1997) feedback consistency effects were actually attributable to the lack of control of familiarity. In any case, because we have equated on these dimensions rather than selecting our stimuli randomly, our item analyses also suffered from a negative bias.

Second, because of this process of equating on numerous dimensions, our stimulus set consisted of a relatively small number of items (i.e., 12) per condition. Thus, in addition to the fact that item analyses are not powerful because of their negative bias, they were even weaker because of the small size of our stimulus set. As a result, their ability to pick up even large effects was severely limited.

Finally, the point needs to be made that even if we had found a significant $F$ in our item analyses, there would be no legitimacy in arguing that we can now "generalize over items" (regardless of whether we had selected the items randomly). Generality is not a statistical issue. As Wike and Church (1976) noted, "generality is not obtained simply by selecting $p$ levels randomly" (p. 253) and "generality is not achieved by using one or another statistical procedure in analyzing the results of a single experiment" (p. 254); rather, "generalization of the results of single experiments must be done on a basis of judgment" (p. 254). Thus, because of the inherent statistical problems in item analyses and the complete lack of a payoff in terms of generalizability, we do not believe that the item analyses, regardless of how they turned out, are of any real value in understanding what occurred in these experiments.

Wike and Church (1976) went on to state that "generality is attained by a variety of techniques of replication" (p. 254). Thus, it is important to note that Kinoshita and Woollams (1996) also recently reported a significant regularity effect for a different set of low-frequency words in English using a go/no-go naming task. In addition, as in Coltheart and Rastle (1994), Kinoshita and Woollams investigated the sizes of regularity effects as a function of the phonemic position of the irregularity. According to Coltheart and Rastle, the size of the regularity effect in standard naming tasks decreases as a function of the left-to-right phonemic position of the irregularity. Coltheart and Rastle further suggested that this modulation of the regularity effect results from the serial nature of the assembly route. That is, when the irregularity is near the end of the word, the assembly route will output the incorrect, regularized phoneme relatively late. Thus, there would be a higher chance of collecting a correct phonological code from the lexical route before the assembly route produced the incorrect, conflicting output. As such, the regularity effect should be smaller when the irregularity was near the end of the word.

On the basis of this analysis, Kinoshita and Woollams (1996) suggested that not only would there be no reason to expect any regularity effect in go/no-go naming but also that there would be no reason for any regularity effect that was observed to be modulated by letter position because the phonological coding involved in this task should be driven only at the lexical level. Nonetheless, as in the standard naming task, the left-to-right modulation of the regularity effect was observed in the go/no-go naming task. ${ }^{5}$ Thus, in addition to providing a basis for generalizing our results beyond the set of words we used, Kinoshita and Woollams's

\footnotetext{
${ }^{5}$ Kinoshita and Woollams (1996) did observe a significant regularity effect in their lexical-decision task. However, this regularity effect was not modulated by the position of the irregularity, indicating that it was not due to the same process that led to the regularity effect in naming and go/no-go naming. On the basis of their entire set of results, Kinoshita and Woollams concluded that, contrary to Coltheart and Rastle (1994), the left-to-right modulation of the regularity effect in naming is not due to phonological
} 
data also provide support for the claim that we ultimately offer: that the phonological coding process involved in go/no-go naming is highly similar to the phonological coding process involved in standard naming.

One final point that should be noted about the results of Experiment 4 is that unlike in Hino and Lupker (1998), the sizes of frequency effects in the go/no-go naming task (94 $\mathrm{ms}$ for regular words and $133 \mathrm{~ms}$ for irregular words) were only larger than those in the LDT (92 and $100 \mathrm{~ms}$, respectively) for irregular words. As we argue in the General Discussion section, we believe that this difference in the patterns of frequency effects is readily explainable in terms of the differences between English and Japanese.

\section{Experiment 5}

Parallelling the results reported by Hino and Lupker (1998) using Japanese words, we observed significant Frequency $\times$ Regularity interactions in go/no-go naming and standard naming but not in lexical decision in English. Before drawing any further conclusions, one other issue must be addressed. One important difference between the go/no-go naming task and the LDT is certainly that the former requires phonological coding whereas the latter does not. There is, however, an additional difference between the two tasks. That is, whereas responses are required for only half the stimuli in the go/no-go naming task, responses are required for all the stimuli in the LDT. As noted by Hino and Lupker, this difference in the nature of responding does make the comparison between tasks somewhat difficult because the nature of the supposedly identical subprocesses may be different in the two situations (e.g., Donders, 1969). Thus, one cannot unambiguously conclude that the emergence of the interaction in the go/no-go naming task was due to the phonological coding process.

To address this issue, we used a go/no-go LDT in Experiment 5. In this task, participants were asked to press a key only if the stimulus was a word. Because no phonological coding would be required in this task, if the Frequency $x$ Regularity interaction in go/no-go naming really is due to the phonological coding process and not to the fact that responses are required only to half the stimuli, we would not expect this interaction to emerge in Experiment 5.

\section{Method}

Participants. Twenty-six undergraduates from the University of Western Ontario participated in this experiment for course credit. All were native English speakers and had normal or corrected-tonormal vision. None had participated in the previous experiments.

Stimuli. The stimuli were the same as those used in Experiments 1 and 4.

Procedure. Participants were tested individually. Participants were asked to press a key on the response box using their dominant hand only if the stimulus was a word. Right-handed participants

coding, but rather it reflects the serial nature of the articulatory process following phonological coding. This process is not a component of either the current dual-route or parallel distributed processing models. were asked to press the rightmost key on the response box and left-handed participants were asked to press the leftmost key. In all other respects, the procedure was identical to that used in Experiment 4.

\section{Results}

Lexical-decision latencies less than $250 \mathrm{~ms}$ or greater than $1500 \mathrm{~ms}$ were classified as errors. Thus, 23 data points from the experimental word trials $(1.84 \%)$ were considered as errors and excluded from the latency analyses. Mean lexical-decision latencies for correct responses and mean error rates were calculated across participants and items separately. The mean lexical-decision latencies and error rates (based on the 48 experimental word trials) averaged over the participants are presented in Table 6.

Subject and item means of lexical-decision latencies and error rates (based on the experimental word trials) were submitted to separate ANOVAs. In the analyses of lexicaldecision latencies, the main effect of frequency was significant in both the subject and the item analyses, $F_{s}(1,25)=$ $124.18, M S E=3,027.97, p<.001 ; F_{i}(1,44)=34.60$, $M S E=5,180.12, p<.001$, reflecting the fact that lexicaldecision latencies were faster for high-frequency words than for low-frequency words. However, neither the main effect of regularity, $F_{s}(1,25)=0.22, M S E=3,752.92 ; F_{i}(1,44)=$ $0.07, M S E=5,180.12$, nor the interaction between regularity and frequency, $F_{s}(1,25)=1.50, M S E=2,011.47 ; F_{i}(1$, 44) $=0.30, M S E=5,180.12$, was significant in either analysis.

In the analyses of error rates, the main effect of frequency was significant in both analyses, $F_{s}(1,25)=34.40, M S E=$ $29.51, p<.001 ; F_{i}(1,44)=15.33, M S E=30.57, p<.001$, reflecting the fact that responses to high-frequency words were more accurate than responses to low-frequency words. Neither the main effect of regularity, $F_{s}(1,25)=0.16$, $M S E=36.57 ; F_{i}(1,44)=0.09, M S E=30.57$, nor the interaction between regularity and frequency, $F_{s}(1,25)=$ $0.03, M S E=20.11 ; F_{i}(1,44)=0.01, M S E=30.57$, was significant in either analysis.

\section{Discussion}

The main purpose of Experiment 5 was to evaluate the hypothesis that the Frequency $\times$ Regularity interaction

Table 6 Mean Lexical-Decision Latencies (in ms) and Error Rates (\%) in the Go/No-Go Lexical-Decision Task in Experiment 5

\begin{tabular}{|c|c|c|c|c|c|}
\hline \multirow[b]{3}{*}{ Regularity } & \multicolumn{4}{|c|}{ Word frequency } & \multirow{3}{*}{$\begin{array}{c}\mathbf{R T} \\
\text { difference }\end{array}$} \\
\hline & \multicolumn{2}{|c|}{ Low } & \multicolumn{2}{|c|}{ High } & \\
\hline & $M$ & ER & $M$ & ER & \\
\hline $\begin{array}{l}\text { Regular } \\
\text { Irregular } \\
\text { RT difference }\end{array}$ & $\begin{array}{r}712 \\
717 \\
5\end{array}$ & $\begin{array}{l}7.05 \\
7.35\end{array}$ & $\begin{array}{r}602 \\
586 \\
-16\end{array}$ & $\begin{array}{l}0.64 \\
1.28\end{array}$ & $\begin{array}{l}110 \\
131\end{array}$ \\
\hline
\end{tabular}

Note. The mean error rate for nonwords was $6.54 \% . \mathrm{ER}=$ error rate; $\mathrm{RT}=$ reaction time. 
observed in Experiment 4 might have been attributable to the nature of the subprocesses involved in a go/no-go task due to the fact that a response is required only to half the stimuli. The lack of a Frequency $\times$ Regularity interaction in the go/no-go LDT clearly indicates that it was not. Rather, as argued earlier, because this interaction arises only when participants must make a rapid naming response (i.e., Experiments 2 and 4), it appears to be due to phonological coding processes.

Note also that the frequency effect was numerically larger in the go/no-go LDT (121-ms effect) than in the standard LDT (97-ms effect) in the latency data. Furthermore, the frequency effect was numerically smaller in the go/no-go task (6.24\% effect) than in the standard task (8.34\% effect) in the error data. These results, although weaker, are highly consistent with those in Hino and Lupker (1998). As noted, this issue of the sizes of the frequency effects across tasks and languages is discussed in the General Discussion section.

\section{General Discussion}

There are now a number of reports in the literature indicating that frequency interacts with spelling-to-sound regularity/consistency in standard naming tasks (e.g., Andrews, 1982; Brown et al., 1994; Frost et al., 1987; Glushko, 1979; Hino \& Lupker, 1996, 1998; Monsell et al., 1989; Seidenberg et al., 1984; Waters \& Seidenberg, 1985). The lexical-selection/dual-route framework suggests that this interaction is due to the different relative contributions of the lexical and assembly routes depending on word type. On the other hand, the PDP framework suggests that this interaction is due to the fact that frequency and regularity/consistency are both reflected in the weights on connections between orthographic and phonological units. Thus, these two frameworks provide much different accounts of this Frequency $x$ Regularity/Consistency interaction.

To discriminate between these alternatives, Hino and Lupker (1998) asked whether a Frequency $\times$ Regularity interaction would be observed even when phonological coding is preceded by lexical-decision operations, that is, in go/no-go naming tasks in which participants are asked to name a stimulus aloud only if it is a word. According to the lexical-selection/dual-route framework, the process of making a lexical decision involves determining whether there is a corresponding lexical representation for a given stimulus (e.g., Coltheart, 1978; Coltheart et al., 1993). As such, the lexical-selection process should be finished well before a phonological code would be required in a go/no-go naming task. Thus, whereas the lexical and assembly routes would both be operative in the standard naming task, the phonological coding process involved in the go/no-go naming task should be driven solely by lexical information (see Paap et al., 1987).

The PDP framework, on the other hand, does not predict any essential differences in the phonological coding involved in these two tasks. In the standard naming task, this framework suggests that phonological codes are computed from orthographic input activation based on the weights on connections between units. In addition, because this framework does not involve the notion of lexical representations, lexical decisions are assumed to be made (during a decisionmaking process) based on some index of familiarity, typically one based on orthographic information. Thus, if phonological codes need to be computed after making lexical decisions (i.e., in a go/no-go naming task), this phonological coding process would have to be driven by the orthographic activation, just as in the standard naming task. As such, there would be no essential differences in phonological coding between the standard and go/no-go naming tasks.

In their examination of word frequency effects for kanji and katakana words, Hino and Lupker (1998) observed a Frequency $\times$ Script Type interaction both in the standard and go/no-go naming tasks, whereas there was no interaction in the standard and go/no-go LDTs. These results suggest that (a) the Frequency $\times$ Script Type interaction arises only when a task involves a phonological coding process and (b) the phonological coding processes involved in the standard and go/no-go naming tasks have similar characteristics in terms of their sensitivity to frequency and script type.

The PDP framework incorporates these conclusions quite naturally, whereas, as noted, the lexical-selection/dual-route framework suggests that the phonological coding process would be qualitatively altered depending on whether it is preceded by lexical-decision operations. Nonetheless, as Hino and Lupker (1998) argued, it may be possible to explain these results within the lexical-selection/dual-route framework.

Japanese kanji and katakana words differ not only in terms of their spelling-to-sound regularity/consistency but also in terms of their orthographic characteristics. Thus, lexical units for kanji and katakana words may differ from one another in that they may incorporate some (differential) orthographic information. If so, and if the lexical phonological coding process in the go/no-go naming task is driven by these orthographically dependent lexical units, this process may be sensitive to the script difference. In addition, if this process is assumed to be sensitive to word frequency, as also suggested by Hino and Lupker's (1998) results, an interaction between these two factors during the lexical phonological coding process would naturally follow. Thus, this type of model could also account for the Frequency $\times$ Script Type interactions in the standard and go/no-go naming tasks.

The main purpose of the present research was to examine this possibility. Instead of using kanji and katakana words, we used regular and irregular English words because there would not appear to be any basic differences between regular and irregular words in terms of either their orthographic characteristics or the nature of their (presumably amodal) lexical units. Thus, if the Frequency $\times$ Script Type interaction in the go/no-go naming task reported by Hino and Lupker (1998) were due to the fact that lexical units are script dependent in Japanese, the analogous interaction (i.e., Frequency $\times$ Regularity) should not be observed in go/ no-go naming in English.

Using English stimuli, our results were highly similar to those reported by Hino and Lupker (1998) using Japanese 
stimuli. That is, a Frequency $\times$ Regularity interaction was observed in the standard and go/no-go naming tasks, whereas no interaction was observed in the standard and go/no-go LDTs. These results, then, seem to suggest that the interaction in the go/no-go naming task is not due to having script-dependent lexical units. Rather, it appears that spellingto-sound regularity is what is responsible for producing the Frequency $\times$ Regularity. interaction in the go/no-go naming task as well as in the standard naming task.

Although Frequency $\times$ Regularity/Consistency interactions are the norm in standard naming tasks (e.g., Andrews, 1982; Brown et al., 1994; Frost et al., 1987; Glushko, 1979; Hino \& Lupker, 1996, 1998; Monsell et al., 1989; Seidenberg et al., 1984; Waters \& Seidenberg, 1985) including the present Experiment 2, Jared (1997) recently suggested that the lack of consistency effects for high-frequency words is due to the weak manipulation of the spelling-to-sound inconsistency for high-frequency words. In fact, Jared reported significant consistency effects for both high- and low-frequency words when the degree of inconsistency for high-frequency inconsistent words was manipulated as strongly as that for low-frequency inconsistent words.

These results suggest that both the lexical-selection/dualroute framework and the PDP framework have to be modified to account for the significant consistency effect for high-frequency words. In particular, the lexical-selection/ dual-route framework needs to be modified to assume either a larger degree of contribution of the assembly route in the naming of high-frequency words or the effects of consistency on the lexical route are more potent than initially assumed. Modification of the PDP framework would require making changes in the weights on connections between the orthographic and phonological units for high-frequency words. Specifically, those weights would need to reflect the impact of the spelling-to-sound correspondences of the similarly spelled words to at least some degree.

Because our irregular words were drawn from the previous literature, our high-frequency irregular words were undoubtedly not particularly strongly inconsistent (relative to our low-frequency irregular words). Thus, the Frequency $x$ Regularity interaction in our Experiment 2 certainly does not provide evidence against Jared's (1997) claims.

The important points here, however, are that in the present research, the same words were used in all experiments and that this Frequency $\times$ Regularity interaction was task dependent. That is, it was observed in both the standard and go/no-go naming tasks but not in the standard and go/no-go LDTs. Thus, even if the interaction itself was attributable to different levels of irregularity in the high- and lowfrequency words, the effects of the spelling-to-sound regularity were limited to and similar across the standard and go/no-go naming tasks. Thus, again, regardless of whether Jared (1997) is correct, our results suggest that spelling-tosound regularity/consistency is what is responsible for producing the Frequency $\times$ Regularity interaction in the two naming tasks and that this factor has little effect in tasks not requiring phonological coding.

\section{Cross-Task Comparisons of Frequency Effects}

Go/no-go naming versus standard lexical decision and standard naming. Hino and Lupker (1998) observed that frequency effects were significantly larger in the go/no-go naming task than in the standard LDT for their Japanese stimuli. As previously noted, this finding was not predicted by the lexical-selection/dual-route account. Because both the standard lexical-decision and go/no-go naming tasks require lexical-decision operations, the lexical-selection process should be involved in both tasks (e.g., Coltheart, 1978; Coltheart et al., 1993). Thus, if frequency effects are due to the lexical-selection process, the sizes of the frequency effects should be identical in the two tasks. The fact that the frequency effect was larger in the go/no-go naming task than in the standard LDT therefore seemed to suggest that the go/no-go naming task must involve an extra frequency-sensitive process that is not involved in the LDT. Hino and Lupker suggested that this might be the phonological coding process that follows an implicit "word" decision in a go/no-go naming task. That is, to account for this result, one needs to assume both the existence of such a phonological coding process and that this process is sensitive to word frequency.

A similar type of argument was made to explain why Hino and Lupker (1998) found that the frequency effect for kanji words was larger in the go/no-go naming task than in the standard naming task. Because the assembly route presumably does not contribute to the naming of kanji words, phonological coding would be done only at the lexical level in both tasks. Thus, the lexical-selection/dual-route framework suggests that the sizes of frequency effects for kanji words should be identical in the two tasks. The larger frequency effect for kanji words in the go/no-go naming task than in the standard naming task would suggest that the go/no-go naming task involves an extra frequency-sensitive process that is not involved in the standard naming task. An obvious possibility would be the decision-making process. Thus, to explain this result, one would need to assume that the decision-making process is sensitive to word frequency. What should be noted, of course, is that making the assumptions that both phonological coding and decision making are sensitive to word frequency is essentially an endorsement of Balota and Chumbley's $(1984,1985)$ position that word frequency effects are mainly due to taskspecific processes.

What should also be noted, however, is that in the present studies, these cross-task comparisons did come out slightly differently than they did in Hino and Lupker (1998). In particular, the differences in the sizes of the frequency effects in the standard lexical-decision and go/no-go naming tasks were noticeably smaller with English words than with Japanese words. An obvious question is, Can this difference between languages be explained?

According to the account just outlined, frequency effects are larger in the go/no-go naming task than in the standard LDT because the frequency effect in the go/no-go naming task is produced by both the decision-making and phonological coding processes, whereas the frequency effect in the 
standard LDT does not involve the phonological coding process. Therefore, any size difference in frequency effects between the two tasks would be due to the contributions of the phonological coding process. The question then becomes, how large would the frequency effect produced by the phonological coding process be expected to be in the present experiments?

If one assumes that the phonological coding processes involved in the standard and go/no-go naming tasks are similar in terms of their sensitivity to word frequency, the size difference in frequency effects between the standard lexical-decision and go/no-go naming tasks would correspond to the sizes of frequency effects in the standard naming task. That is, the larger the frequency effect in the standard naming task, the larger the difference in frequency effects between the lexical-decision and go/no-go naming tasks. In fact, consistent with this suggestion, frequency effects in standard naming tasks were much larger in Hino and Lupker's (1998) studies (41- and 94-ms effects for katakana and kanji words, respectively) than in the present studies (12- and 32-ms effects for regular and irregular words, respectively). Therefore, the smaller differences in the sizes of the frequency effects between the standard lexical decision and go/no-go naming in English does not appear to be inconsistent with the task-specific account of word frequency effects suggested by Hino and Lupker.

The fact that the frequency effects were noticeably larger in Japanese than in English in the naming task (especially for the katakana words compared with regular words) does require some discussion. A possible reason that frequency effects were larger for Japanese katakana words than for regular English words is that Japanese katakana words actually have a larger degree of spelling-to-sound inconsistency than regular English words because of issues involved in determining their accent patterns. That is, although katakana is a shallow orthography, there is some variability in terms of how the syllables are accented when pronouncing katakana words. This variability in accent would appear to make the spelling-to-sound correspondences a bit more ambiguous for katakana words than for regular English words, especially monosyllabic English words. In addition, this variability in accent patterns may have had a larger impact on naming low-frequency words than on naming high-frequency words, as the degree of spelling-to-sound irregularity/inconsistency was presumably larger for lowfrequency words than for high-frequency words (e.g., Jared, 1997). If so, the expected result would be a larger frequency effect for katakana words than for regular English words in standard naming tasks.

Using this same logic, the spelling-to-sound correspondences would also be more ambiguous for Japanese kanji words than for irregular English words, which would at least partly explain why the frequency effects were so much larger for kanji words than for irregular words. In addition, however, there is another important difference between irregular English words and kanji words. Irregular English words are only partly irregular. For example, the irregular word pint is only $25 \%$ irregular and $75 \%$ regular in terms of its spelling-to-sound correspondences. On the other hand, when a kanji word consists of two kanji characters, each of which possesses on-reading and kun-reading pronunciations, the character-to-sound correspondences for the kanji word would be highly ambiguous. Thus, given this greater degree of irregularity for Japanese kanji words than for irregular English words, both in terms of accent and in terms of character-to-sound correspondences, it is not at all surprising that word frequency effects in the standard naming tasks are larger for Japanese kanji words than for irregular English words because, again, these irregularities were probably larger for low-frequency words than for high-frequency words (e.g., Jared, 1997).

As such, our suggestion would be that the larger frequency effects in naming in Japanese (Hino \& Lupker, 1998) than in English (the present results) were mostly likely due to the different degrees of irregularity in the spelling-tosound correspondences for Japanese and English words, especially for low-frequency words.

Go/no-go lexical decision versus standard lexical decision. Hino and Lupker (1998) noted that there was also a large difference in the size of the frequency effects in their standard and go/no-go LDTs. They provided the following account of that difference. Because participants are asked to make a rapid response to both word and nonword stimuli in the standard task, when an unfamiliar stimulus is presented, participants would tend to want to make a rapid "nonword" response. Thus, in the standard LDT, unfamiliar lowfrequency words would tend to produce error responses rather than long latencies.

In the go/no-go task, however, there is no pressure to make a rapid "nonword" decision because participants are required to respond only to word stimuli. That is, when an unfamiliar stimulus is presented, participants do not need to terminate processing by making a rapid "nonword" response. Because participants can use more time in the processing of an unfamiliar stimulus, it would increase the chance of there being a correct but delayed "word" response to unfamiliar word stimuli. Thus, error rates for unfamiliar low-frequency words would decrease in the go/no-go LDT, however, at the same time, the "word" responses for the low-frequency words would also be accompanied by relatively longer response latencies. As a consequence, frequency effects would tend to be larger in the go/no-go task than in the standard task in the latency data, whereas the reverse would tend to be true in the error data.

A similar pattern to that observed by Hino and Lupker (1998) was also observed in the present experiments (although the pattern was weaker in the present experiments). That is, the frequency effect was approximately $24 \mathrm{~ms}$ larger in the go/no-go LDT than in the standard LDT in the present experiments (in comparison, the difference reported by Hino and Lupker was $55 \mathrm{~ms}$ ). Similarly, the frequency effect in the error rate data was $2.1 \%$ smaller in the go/no-go LDT than in the standard LDT in the present experiments (in comparison, the difference reported by Hino and Lupker was $15.4 \%$ ). Thus, even though there was a quantitative difference between these two sets of studies, this aspect of the present results appears to be fully consistent with Hino and Lupker's account. That is, the task-specific nature of the frequency 
effects in the standard and go/no-go LDTs suggests that these results are more consistent with a task-specific account.

\section{The Frequency $\times$ Regularity Interaction in Go/No-Go Naming}

Lexical-selection/dual-route accounts. Because a Frequency $\times$ Regularity interaction was observed in both the standard and go/no-go naming tasks, we have argued that the phonological coding processes involved in these two tasks must have highly similar characteristics. Thus, to explain these results in terms of the lexical-selection/dual-route framework, one would need to assume that the lexical and assembly routes are both operative in both tasks, even when the phonological coding process is preceded by lexicaldecision operations.

For the assembly route to be operative during the phonological coding process in the go/no-go naming task, this process presumably has to be driven by subword-level orthographic codes. As Hino and Lupker (1998) have argued, however, it does not seem likely that the phonological coding in go/no-go naming would be driven by lower level orthographic codes because a more recently activated, and presumably more stable, amodal lexical code should be available to control the phonological coding process in that task. On the other hand, one must consider the possibility that if one makes a slightly different set of assumptions about the nature of processing in go/no-go naming, specifically assumptions about the order in which the processing operations are carried out, the implications for the dual-route/ lexical-selection account might be different. In particular, a different set of assumptions may create a situation in which both orthographic codes and the assembly route do play a role in go/no-go naming in English.

Consider, for example, the possibility that the lexicaldecision and phonological coding processes in go/no-go naming are assumed to go on in parallel, rather than quasi-sequentially. Whichever of these processes finishes last would control the nature of the go/no-go naming latencies. If one were to further suggest that the lexicaldecision process was completed first (possibly because participants made their decisions on information such as overall lexical activation, as suggested by Grainger and Jacobs, 1996), the phonological coding process would be identical in both standard and go/no-go naming. That is, the phonological coding process would be driven by orthographic codes and the assembly route would be operative in both tasks. The result would be a Frequency $\times$ Regularity/ Consistency interaction in the go/no-go naming task as well as in the standard task.

Unfortunately, this idea quickly runs into a problem. If the lexical-decision operations do go on in parallel with the phonological coding operations and the decision-making operations always finish first, one would predict that the results in the go/no-go naming task and the standard naming task would be virtually identical. Such was clearly not the case. Certainly, the two tasks both did show a Frequency $X$ Regularity interaction. Furthermore, they also showed simi- lar size regularity effects for both high- and low-frequency words. The same was more or less true in Japanese, although the high- and low-frequency script effects in Hino and Lupker (1998; which would be the parallels to the regularity effects) were not as similar across tasks as the high- and low-frequency regularity effects in the present studies. Nonetheless, the remainder of the results (in both languages) were not similar in the two tasks. In particular, both the overall latencies and the frequency effects were substantially larger in go/no-go naming than in standard naming.

Conversely, what if one considers the possibility that the lexical-decision process is the last to finish? This assumption would be even less viable because it would imply that the go/no-go naming results would mimic the lexical-decision results. In particular, the go/no-go naming task should produce overall latencies and frequency effects that are similar to those observed in the LDT. Most importantly, there should be no regularity effect. In the present results, the only aspect of these predictions that held is the equivalent size frequency effects for the regular words $(92 \mathrm{~ms}$ in standard lexical decision and $94 \mathrm{~ms}$ in go/no-go naming). Furthermore, the main predictions of this account (no Frequency $\times$ Script Type interaction, equivalent overall latencies, and identical frequency effects in the lexicaldecision and go/no-go naming tasks) would all be incorrect for the Japanese data as well (Hino \& Lupker, 1998).

Interestingly, there is another possibility that would appear to be a bit more viable. That is, one could assume that the lexical-decision and phonological coding processes do run quasi-sequentially, rather than running in parallel, but that the phonological coding process actually is accomplished first (M. Coltheart, personal communication, November 23, 1997). ${ }^{6}$ More concretely, in this conceptualization, which is based on the dual-route cascaded model (Coltheart et al., 1993; Coltheart \& Rastle, 1994), the assumption is that both lexical and phonological activation would start building up as soon as a letter string was presented (i.e., in the standard fashion). Thus, both the lexical and assembly routes would be operative and in fact would control the phonological coding process exactly as they do in a standard naming task. Only when phonological coding was completed would participants make their implicit lexical decision, and they would do so simply by checking to see if a single lexical unit had been selected. If so, they would output the result of their phonological coding process. If not, they would remain silent.

If one further assumes that this checking process is time-consuming, the basic prediction that this idea makes is that the results in the go/no-go naming task will be identical to those in the standard naming task, except that the overall latencies will be elevated by a constant (the time to carry out the check). At a more detailed level, the following would be the predictions: First, there would be a Frequency $x$ Regularity interaction in the go/no-go naming task because the low- and high-frequency regularity effects would be

\footnotetext{
${ }^{6}$ We would like to thank Max Coltheart for suggesting some possibilities for how the dual-route cascaded model could do go/no-go naming.
} 
identical to those in standard naming (because the phonological coding operations in the two tasks are identical). As noted, these effects were highly similar in the present experiments and the parallel (script) effects were somewhat similar in the experiments using Japanese words (Hino \& Lupker, 1998). Second, go/no-go naming latencies should be longer than standard naming latencies because the checking process involved in the go/no-go naming task is timeconsuming. This prediction also holds. Third, the frequency effects should be identical in the standard and go/no-go naming tasks. On this count, of course, this conceptualization runs into a serious problem because the frequency effects in go/no-go naming are always substantially larger than those in standard naming.

To fix this problem, one would have to make the further assumption that the checking process (which one could think of as a "decision-making" process) was frequency sensitive. That is, one would have to assume that participants in these experiments do not take the simple existence of a selected lexical unit as evidence that the letter string is a word. Rather, they go through some sort of frequency-sensitive analysis process to make that determination.

The assumption of a frequency-sensitive decision-making process is, of course, an assumption that we have argued for both in this article and previously, and, as noted, we are not the first. For example, some researchers (e.g., Balota \& Chumbley, 1984; Besner, 1983; Besner \& McCann, 1987; Seidenberg et al., 1984; Waters \& Seidenberg, 1985) have suggested that lexical decisions can be made based on the orthographic familiarity of the stimuli themselves, which would be evaluated independently of the lexical-selection process. In this type of conceptualization, frequency effects arise naturally from the fact that high-frequency words are more familiar than low-frequency words. In contrast, what would be analyzed when this "lexical checking process" is being carried out would be the status of lexical units. Because lexical units are presumed to be memorial representations that are essentially independent of the stimuli that activated them, it is unclear how one could conceive of this lexical checking process in a way that would allow it to be frequency sensitive. Nonetheless, it does appear that some sort of process of this nature must be assumed in order to allow this type of account to explain the go/no-go naming results. The bottom line, then, is that by adopting a frequency-sensitive decision-making process that is independent of lexical selection and hence assuming that lexical selection itself often plays little role in making lexical decisions, the present results as well as those in Hino and Lupker (1998) could be accounted for based on the lexicalselection/dual-route framework. What is less clear is whether these assumptions would actually be consistent with the basic tenets of the dual-route framework (e.g., Coltheart et al., 1993).

PDP accounts. On the other hand, as Hino and Lupker (1998) have argued, all these results, as well as the assumption that there are frequency-sensitive decisionmaking (and phonological coding) processes, are highly consistent with the general PDP framework. In this type of framework, lexical decisions and hence this decision- making process are assumed to be based on some sort of familiarity index. In our view, this index is based primarily on orthographic information; however, semantic information also likely plays a role. Phonological information can certainly be made to play a role, too; however, this appears to be mostly likely to happen when the other types of information are either impoverished or possibly slow to arrive (e.g., Hino \& Lupker, 1996).

A caveat to this conclusion is necessary because, as previously noted, all currently implemented PDP models do have some problems accounting for the available data at a quantitative level (e.g., Balota \& Spieler, in press; Besner, in press; Besner et al., 1990; Fera \& Besner, 1992; Spieler \& Balota, 1997). In addition, modifications would be necessary to account for Jared's (1997) results by allowing an influence from spelling-to-sound consistency on the naming of high-frequency words. Given these problems, more development would be necessary before one can make an unambiguous statement about the ability of this type of framework to successfully model performance in these tasks.

\section{Conclusions}

The effects of word frequency and spelling-to-sound regularity were examined using standard lexical-decision, standard naming, go/no-go naming, and go/no-go LDTs. A Frequency $\times$ Regularity interaction was observed in the standard and go/no-go naming tasks, whereas no interaction was observed in the standard and go/no-go LDTs. Because this interaction was observed only when participants had to make a rapid naming response, the interaction appears to be due to phonological coding and appears to arise regardless of whether lexical-decision operations are also required. Because the PDP frameworks do not involve the notion of lexical representations and hence do not distinguish between the phonological coding operations carried out in a standard naming task and the phonological coding operations carried out when a lexical decision must also be made, the finding of similar interactions in the standard and go/no-go naming tasks is highly compatible with those frameworks.

On the other hand, the lexical-selection/dual-route framework seems to have some difficulty explaining this interaction in the go/no-go naming task. Because phonological coding is initiated based on subword-level orthographic codes in the standard naming task, the interaction is easily explained in that task. However, because lexical representations are assumed to play a central role in making lexical decisions, when the phonological coding process is preceded by the lexical-decision operations, the phonological coding process should be driven only at the lexical level. Thus, it is unclear why the same interaction would arise in the standard and go/no-go naming tasks. Different assumptions about the way the go/no-go naming task is carried out may ultimately allow this model to account for these results. At present, however, there does not appear to be a good way to do this without either noticeably changing the nature of the framework or introducing new problems. 


\section{References}

Andrews, S. (1982). Phonological recoding: Is the regularity effect consistent? Memory \& Cognition, 10, 565-575.

Balota, D. A., \& Chumbley, J. I. (1984). Are lexical decisions a good measure of lexical access? The role of word frequency in the neglected decision stage. Journal of Experimental Psychology: Human Perception and Performance, 10, 340-357.

Balota, D. A., \& Chumbley, J. I. (1985). The locus of wordfrequency effects in the pronunciation task: Lexical access and/or production? Journal of Memory and Language, 24, 89-106.

Balota, D. A., \& Spieler, D. H. (in press). The utility of item-level analyses in model evaluation: A reply to Seidenberg and Plaut (1998). Psychological Science.

Becker, C. A. (1980). Semantic context effects in visual word recognition: An analysis of semantic strategies. Memory \& Cognition, 8, 493-512.

Besner, D. (1983). Basic decoding components in reading: Two dissociable feature extraction processes. Canadian Journal of Psychology, 37, 429-438.

Besner, D. (in press). Basic processes in reading: Multiple routines in localist and connectionist models. In P. A. McMullen \& R. M. Klein (Eds.), Converging methods for understanding reading and dyslexia. Cambridge, MA: MIT Press.

Besner, D., \& McCann, R. S. (1987). Word frequency and pattern distortion in visual word identification and production: An examination of four classes of models. In M. Coltheart (Ed.), Attention and performance XII (pp. 201-219). Hillsdale, NJ: Erlbaum.

Besner, D., \& Smith, M. C. (1992). Basic processes in reading: Is the orthographic depth hypothesis sinking? In R. Frost \& L. Katz (Eds.), Orthography, phonology, morphology, and meaning (pp. 45-66). Amsterdam: North-Holland.

Besner, D., Twilley, L., McCann, R. S., \& Seergobin, K. (1990). On the association between connectionism and data: Are a few words necessary? Psychological Review, 97, 432-446.

Brown, P., Lupker, S. J., \& Colombo, L. (1994). Interacting sources of information in word naming: A study of individual differences. Journal of Experimental Psychology: Human Perception and Performance, 20, 537-554.

Clark, H. H. (1973). The language-as-fixed-effect fallacy: A critique of language statistics in psychological research. Journal of Verbal Learning and Verbal Behavior, 12, 335-359.

Cohen, J. (1976). Random means random. Journal of Verbal Learning and Verbal Behavior, 15, 261-262.

Coltheart, M. (1978). Lexical access in simple reading tasks. In G. Underwood (Ed.), Strategies of information processing (pp. 151-216). London: Academic Press.

Coltheart, M., Curtis, B., Atkins, P., \& Haller, M. (1993). Models of reading aloud: Dual-route and parallel-distributed-processing approaches. Psychological Review, 100, 589-608.

Coltheart, M., Davelaar, E., Jonasson, J. T., \& Besner, D. (1977). Access to the internal lexicon. In S. Dornic (Ed.), Attention and performance VI (pp. 535-555). New York: Academic Press.

Coltheart, M., \& Rastle, K. (1994). Serial processing in reading aloud: Evidence for dual-route models of reading. Journal of Experimental Psychology: Human Perception and Performance, 20, 1197-1211.

Donders, F. C. (1969). On the speed of mental processes: 18681869. Acta Psychologica, 30, 412-431.

Fera, P., \& Besner, D. (1992). The process of lexical decision: More words about a parallel distributed processing model. Journal of Experimental Psychology: Learning, Memory, and Cognition, $18,749-764$.
Forster, K. I. (1976). Accessing the mental lexicon. In R. J. Wales \& E. Walk (Eds.), New approaches to language mechanisms (pp. 257-287). Amsterdam: North-Holland.

Forster, K. I., \& Chambers, S. M. (1973). Lexical access and naming time. Journal of Verbal Learning and Verbal Behavior, $12,627-635$.

Frost, R., Katz, L., \& Bentin, S. (1987). Strategies for visual word recognition and orthographic depth: A multilingual comparison. Journal of Experimental Psychology: Human Perception and Performance, 13, 104-115.

Gernsbacher, M. A. (1984). Resolving 20 years of inconsistent interactions between lexical familiarity and orthography, concreteness, and polysemy. Joumal of Experimental Psychology: General, 113, 256-281.

Glushko, R. J. (1979). The organization and activation of orthographic knowledge in reading aloud. Journal of Experimental Psychology: Human Penception and Performance, 5, 674-691.

Grainger, J., \& Jacobs, A. M. (1996). Orthographic processing in visual word recognition: A multiple read-out model. Psychological Review, 103, 518-565.

Hino, Y., \& Lupker, S. J. (1996). The effects of polysemy in lexical decision and naming: An alternative to lexical access accounts. Journal of Experimental Psychology: Human Perception and Performance, 22, 1331-1356.

Hino, Y., \& Lupker, S. J. (1998). The effects of word frequency for Japanese kana and kanji words in naming and lexical decision: Can the dual-route model save the lexical-selection account? Iournal of Experimental Psychology: Human Perception and Performance, 24, 1431-1453.

Jared, D. (1997). Spelling-sound consistency affects the naming of high-frequency words. Journal of Memory and Language, 36, 505-529.

Keppel, G. (1976). Words as random variables. Journal of Verbal Learning and Verbal Behavior, 15, 263-265.

Kinoshita, S., \& Woollams, A. (1996). The left-to-right regularity effect and strategy effects in naming. Manuscript in preparation.

Kucera, H., \& Francis, W. N. (1967). Computational analysis of present-day American English. Providence, RI: Brown University Press.

Mayzner, M. S., \& Tresselt, M. E. (1965). Tables of single-letter and digram frequency counts for various word length and letter position combinations. Psychonomic Monograph Supplements, 1(2), 13-32.

McCann, R. S., \& Besner, D. (1987). Reading pseudohomophones: Implications for models of pronunciation assembly and the locus of word-frequency effects in naming. Journal of Experimental Psychology: Human Perception and Performance, 13, 14-24.

McClelland, J. L., \& Rumelhart, D. E. (1981). An interactive activation model of context effects in letter perception: 1 . An account of basic findings. Psychological Review, 88, 375-407.

Monsell, S. (1991). The nature and locus of word frequency effects in reading. In D. Besner \& G. W. Humphleys (Eds.), Basic processes in reading: Visual word recognition (pp. 148-197). Hillsdale, NJ: Erlbaum.

Monsell, S., Doyle, M. C., \& Haggard, P. N. (1989). Effects of frequency on visual word recognition tasks: Where are they? Journal of Experimental Psychology: General, 118, 43-71.

Morton, J. (1969). Interaction of information in word recognition. Psychological Review, 76, 165-178.

Paap, K. R., McDonald, J. E., Schvaneveldt, R. W., \& Noel, R. W. (1987). Frequency and pronounceability in visually presented naming and lexical decision tasks. In M. Coltheart (Ed.), Attention and performance XII (pp. 221-243). Hillsdale, NJ: Erlbaum. 
Paap, K. R., Newsome, S. L., McDonald, J. E., \& Schvaneveldt, R. W. (1982). An activation-verification model for letter and word recognition: The word-superiority effect. Psychological Review, 89, 573-594.

Parkin, A. J. (1982). Phonological recoding in lexical decision: Effects of spelling-to-sound regularity depend on how regularity is defined. Memory \& Cognition, 10, 43-53.

Parkin, A. J., \& Underwood, G. (1983). Orthographic vs. phonological irregularity in lexical decision. Memory Cognition, 11, 351-355.

Patterson, K., \& Coltheart, V. (1987). Phonological processes in reading: A tutorial review. In M. Coltheart (Ed.), Attention and performance XII (pp. 421-447). Hillsdale, NJ: Erlbaum.

Patterson, K. E., \& Morton, J. (1985). From orthography to phonology: An attempt at an old interpretation. In $\mathrm{K}$. $\mathrm{E}$. Patterson, J. C. Marshall, \& M. Coltheart (Eds.), Surface dyslexia: Neuropsychological and cognitive studies of phonological reading (pp. 335-359). London: Erlbaum.

Peereman, R., Content, A., \& Bonin, P. (1998). Is perception a two-way street? The case of feedback consistency in visual word recognition. Journal of Memory and Language, 39, 151-174.

Plaut, D. C. (1997). Structure and function in the lexical system: Insights from distributed models of word reading and lexical decision. Language and Cognitive Processes, 12, 765-805.

Plaut, D. C., \& McClelland, J. L. (1993). Generalization with componential attractors: Word and nonword reading in an attractor network. Proceedings of the Cognitive Science Society, $15,824-829$.

Plaut, D. C., McClelland, J. L., Seidenberg, M. S., \& Patterson, K. (1996). Understanding normal and impaired word reading: Computational principles in quasi-regular domains. Psychological Review, 103, 56-115.

Pugh, K. R., Shaywitz, B. A., Shaywitz, S. E., Shankweiler, D. P., Katz, L., Fletcher, J. M., Skudlarski, P., Fulbright, R. K., Constable, R. T., Bronen, R. A., Lacadie, C., \& Gore, J. C. (1997). Predicting reading performance from neuroimaging profiles: The cerebral basis of phonological effects in printed word identification. Journal of Experimental Psychology: $\mathrm{Hu}$ man Perception and Performance, 23, 299-318.

Rubenstein, H., Garfield, L., \& Millikan, J. A. (1970). Homographic entries in the internal lexicon. Journal of Verbal Learning and Verbal Behavior, 9, 487-494.

Rumelhart, D. E., \& McClelland, J. L. (1982). An interactive activation model of context effects in letter perception: 2 . The contextual enhancement effect and some tests and extensions of the model. Psychological Review, 89, 60-94.

Seidenberg, M. S. (1992). Beyond orthographic depth in reading: Equitable division of labor. In R. Frost \& L. Katz (Eds.), Orthography, phonology, morphology, and meaning (pp, 85118). Amsterdam: North-Holland.

Seidenberg, M. S., \& McClelland, J. L. (1989). A distributed, developmental model of word recognition and naming. Psychological Review, 96, 521-568.

Seidenberg, M. S., Waters, G. S., Barnes, M. A., \& Tanenhaus, M. K. (1984). When does irregular spelling or pronunciation influence word recognition? Journal of Verbal Learning and Verbal Behavior, 23, 383-404.

Smith, J. E. K. (1976). The assuming-will-make-it-so fallacy. Journal of Verbal Learning and Verbal Behavior, 15, 262-263.

Spieler, D. H., \& Balota, D. A. (1997). Bringing computational models of word naming down to the item level. Psychological Science, 8, 411-416.

Stanovich, K. E., \& Bauer, D. (1978). Experiments on the spelling-to-sound regularity effect in word recognition. Memory \& Cognition, 6, 410-415.

Stone, G. O., Vanhoy, M., \& Van Orden, G. C. (1997). Perception is a two-way street: Feedforward and feedback phonology in visual word recognition. Journal of Memory and Language, 36, 337-359.

Theios, J., \& Muise, J. G. (1977). The word identification process in reading. In N. J. Castellan, D. B. Pisoni, \& G. R. Potts (Eds.), Cognitive theory (Vol. 2, pp. 289-321). Hillsdale, NJ: Erlbaum.

Van Orden, G. C., Pennington, B. F., \& Stone, G. O. (1990). Word identification in reading and promise of subsymbolic psycholinguistics. Psychological Review, 97, 488-522.

Venezky, R. L. (1970). The structure of English orthography. The Hague, The Netherlands: Mouton.

Waters, G. S., \& Seidenberg, M. S. (1985). Spelling-sound effects in reading: Time-course and decision criteria. Memory \& Cognition, 13, 557-572.

Wike, E. L., \& Church, J. D. (1976). Comments on Clark's "The language-as-fixed-effect fallacy." Journal of Verbal Learning and Verbal Behavior, 15, 249-255.

Ziegler, J. C., Montant, M., \& Jacobs, A. M. (1997). The feedback consistency effect in lexical decision and naming. Journal of Memory and Language, 37, 533-554.

\section{Appendix}

\section{Experimental Word and Nonword Stimuli Used in the Experiments}

Low frequency/regular: wade, peel, wail, wick, sock, wink, dock, deed, dusk, rust, sank, beam
Low frequency/irregular: wand, soot, crow, worm, pear, lure, pour, wool, doll, warm, pint, root
High frequency/regular: nine, deep, wall, book, soon, feel, seem, help, best, face, less, take
High frequency/irregular: foot, none, move, says, love, sure, word, door, done, want, give, good
Nonwords: zail, tark, balk, yole, sile, nuck, balt, tink, filk, fard, dosh, filt, fank, seab, molk, cale,
hend, cark, wull, poot, yake, tace, sard, wace, tord, sull, neek, sork, sace, mork, pite, hask,
dath, fost, rame, mook, dast, wint, bave, soat

Received January 26, 1998 